\title{
A DICOTOMIA DO SABER NA ESCOLA DO CAMPO: APORTES EPISTEMOLÓGICOS DA SOCIOLOGIA RURAL
}

\author{
THE DICHOTOMY OF KNOWLEDGE IN THE SCHOOL OF THE FIELD: EPISTEMOLOGICAL CONTRIBUTIONS OF \\ RURAL SOCIOLOGY
}

LA DICOTOMÍA DEL CONOCIMIENTO EN LA ESCUELA DEL CAMPO: CONTRIBUCIONES EPISTEMOLÓGICAS DE LA SOCIOLOGÍA RURAL

\author{
MELO, Manoel Valquer de Melo' \\ QUEDA, Oriowaldo² \\ FERRANTE, Vera Lúcia Silveira Botta ${ }^{3}$
}

\begin{abstract}
RESUMO
O artigo visou analisar a Educação do Campo como uma modalidade educacional difundida como fruto da bandeira de luta pelo direito à terra dos movimentos socioterritoriais do Brasil. A investigação é precedida de um modelo contra-hegemônico que se contrapõe ao conhecimento urbano-centrado imposto pela a Educação Formal. Por outro lado, convém discutir a Escola do Campo, que se reproduz dentro de uma base ideológica positivista, desvinculada do modo de vida dos sujeitos. Desse modo, concebem-se nos espaços pedagógicos da escola, por meio da dicotomia do saber, as contradições históricas que prescindem da superação do saber hegemônico no contexto das classes sociais do campo.
\end{abstract}

Palavras-chave: Escola do Campo. Movimentos Socioterritoriais. Educação Formal. Sociologia Rural.

\section{ABSTRACT}

The article aimed to analyze the field education as an educational modality widespread as a result of the flag of struggle for the right to land of the socio-territorial movements of Brazil. The investigation is preceded by a hegemonic model that neutralizes the knowledge centered on the urban imposed by formal education. On the other hand, it is advisable to discuss the school of the field, which is reproduced within a positivist ideological basis, detached from the way of life of the subjects. Thus, it is conceived in the pedagogical spaces of the school through the dichotomy of knowledge, the historical contradictions that dispense with overcoming the hegemonic knowledge in the context of the social classes of the field.

Keywords: Field School. Socio-territorial Movements. Formal Education. Sociologia Rural.

\section{RESUMEN}

El artículo tenía como objetivo analizar la educación en el campo como una modalidad educativa generalizada como resultado de la bandera de la lucha por el derecho a la tierra de los movimientos socioterritoriales de Brasil. La investigación está precedida por un modelo hegemónico que neutraliza el conocimiento centrado en lo urbano impuesto por la educación formal. Por otro lado, es aconsejable discutir la escuela del campo, que se reproduce dentro de una base ideológica positivista, separada del modo de vida de los sujetos. Así, se concibe en los espacios pedagógicos de la escuela a través de la dicotomía del conocimiento, las contradicciones históricas que no tienen que superar el conocimiento hegemónico en el contexto de las clases sociales del campo.

Palabras clave: Escuela de Campo. Movimientos Socioterritoriales. Educación Formal.

\footnotetext{
${ }^{1}$ Universidade Federal de Alagoas - UFAL - Alagoas - Brasil.

${ }^{2}$ Universidade de Ararraquara - UNIARA - Araraquara/SP - Brasil.

${ }^{3}$ Universidade de Ararraquara - UNIARA - Araraquara/SP - Brasil.
} 


\section{INTRODUÇÃO}

Ao examinarmos a sistematização do modelo educacional voltado para a Escola do Campo, surgiu a necessidade de fazermos uma reflexão sobre o papel da ação educativa na mediação da transformação social dos indivíduos, principalmente daqueles que não se enquadram nas prioridades dos compromissos sociais da política do Estado. Nessa realidade, observamos que a carência do sistema de alfabetização na escola tradicional é excludente, especificamente quando se preza pelo domínio da escrita e da aplicabilidade de práticas educativas imediatistas voltadas para uma escolarização etnocêntrica e apostilada. Desse modo, é necessário que compreendamos os traços contraproducentes que legitima o método urbano-centrado do saber que dicotomiza a produção do conhecimento na Escola do Campo:

\footnotetext{
O problema é que toda ciência contemporânea é urbano-centrada e, pelas suas raízes históricas, comprometida com uma civilização que se considera padrão universal. Pensa-se, portanto, que ela deve ser seguida em seu europeucentrismo cartesiano por todo o resto do mundo. Como tal, em sua razão dualista, criou dicotomias hierarquizadoras - masculino $x$ feminino, cultura $x$ natureza, urbano $x$ rural, homem branco $x$ não-branco, cultura ocidental $x$ as outras - nas quais 0 primeiro polo é sempre valorado em detrimento do segundo. (WHITAKER; FIAMENGUE, 2002, p. 21).
}

A questão acima é útil quando afirmamos que as estratégias de produção do conhecimento, contaminadas pela separação do espaço rural-urbano, têm negligenciado que tais espaços, cartograficamente, estão interconectados e se interpenetram cotidianamente. Desse modo, somos advertidos, como pesquisadores, sobre a necessidade de pensar a questão de maneira dialética, considerando, evidentemente, as especificidades atribuídas aos espaços territoriais ocupados pelas urbanidades e ruralidades.

Nesse percurso, a discussão sobre a abrangência da Educação do Campo como proposta metodológica inovadora para o território rural evidencia os resquícios colonizadores que dificultam a superação em relação à escolarização formal da Escola do Campo. Os desafios teórico-metodológicos apontados pela Sociologia Rural se demonstram como uma tentativa falhada do modelo educacional dicotômico que, tendencialmente, tem separado o conhecimento através dos seus estratagemas binários e dualistas, os quais são empreendidos por formulações cartesianas obrigatórias para o controle do sistema educacional formal.

O determinismo do saber hegemônico se reproduz dentro de uma panaceia de doutrinas educacionais que são impostas à revelia. Contraditoriamente, o que se pretende é um conhecimento homogeneizado e silenciado. Mediante as aspirações teóricas e políticas que tratam da sistematização do ensino para a Escola do Campo, quando partimos da Educação Formal, faz-se necessária uma reflexão sobre o modus operandi de um sistema dito hegemônico, pois:

Toda relação de 'hegemonia' é necessariamente uma relação pedagógica, que se verifica não apenas no interior de uma nação, entre as diversas forças que a compõem, mas em todo o campo internacional e mundial, entre conjuntos de civilizações nacionais e continentais (GRAMSCI, 1999, p. 399, grifo do autor). 
O contexto acima apresentado nos permite emitir considerações preliminares no que diz respeito à condição da desvantagem social que se encontra a população rural, principalmente do que sobra enquanto ação prática para mudar as regras de um jogo desigualitário. De modo geral, existe uma incompatibilidade na operação de um conhecimento que não interage com o ensino e a aprendizagem na compreensão da vida dos sujeitos; respectivamente, associando-se ao descompasso de um modelo educacional que se cristaliza, levando em consideração o desconhecimento dos domínios da ação educativa da clientela escolar do campo.

Com base no que foi exposto, o presente artigo traz como pano de fundo a discussão sobre os saberes hegemônicos que acompanham a relação da educação urbano-centrada na Escola do Campo. O arcabouço teórico-metodológico abordado se baseia, especificamente, em autores e autoras que versam sobre o tema da Educação pelo viés da descolonização do saber hegemônico. Para compreender o modo cindido que separa o rural-urbano na perspectiva educacional, como aportes da Sociologia Rural, foram fundamentais os estudos de Maria Isaura Pereira de Queiroz (1972); Dulce Consuelo Andreatta Whitaker (2008; 2002) e José de Souza Martins (2005; 1986).

Nessa perspectiva, não podemos nos furtar de apontar como tem sido manipulado o discurso oficial do princípio da autoridade sobre a Educação do Brasil, visto que a pauta impositiva visa à validação do processo de cerceamento e controle por parte do domínio dos setores políticos e religiosos do país.

No plano educacional, torna-se um problema crucial a assimetria ideológica que se reproduz do predomínio do urbano sobre o rural em relação à Escola do Campo. Neste processo civilizatório interpretado pela Educacional Formal, o retrato predominante tende a ser uma questão paradoxal que permanece em voga.

Por outro lado, para alcançar uma educação de um ponto de vista não-etnográfico e nãoeurocêntrico, a aglutinação de um novo paradigma educacional, como à Educação do Campo, exige pedagogias adequadas, que enalteçam a integração do jovem do campo em práticas educativas sistêmicas, que clarifiquem e nutram a diversidade, a totalidade e a cosmovisão do território rural. É necessário fazer um contraponto ao modelo conceptivo do saber científico, atrelado ao conhecimento hegemônico urbano-centrado, porque é fundamental compreender os traços que chancelam as formas desigualitárias de tal método.

\section{DA LUTA PELA TERRA À LUTA POR UMA ESCOLA DO CAMPO}

Recorremos aos recursos historiográficos para interpelar sobre a preparação desse cenário de reflexão, disputas políticas e lutas dos trabalhadores rurais pela educação no território. Assim sendo, destacamos alguns antecedentes históricos que remontam a ascensão reivindicatória das populações rurais do Nordeste Brasileiro. Após o período do fim da $2^{a}$ Guerra Mundial, aponta-se a mobilização popular associada ao mote da Reforma Agrária em Vitória de Santo Antão, município localizado na Zona da Mata pernambucana. No que tange à ampliação das conquistas sociais significativas desse movimento, estabeleceram-se novas subjetividades concernentes à formação do lugar do sujeito no meio rural face às condições impostas pelos grandes proprietários de terra da região. Diante das 
exigências de enfrentamento a uma realidade de desigualdade social, a solidariedade, nesse contexto, renasceu da necessidade da organização social de um grito popular:

\begin{abstract}
A mobilização camponesa do Nordeste, que assume a denominação 'Ligas Camponesas', iniciase no Engenho Galiléia, Pernambuco, no ano de 1954. O movimento expande-se rapidamente. Esse crescimento deve-se às condições políticas e sociais favoráveis e explica-se pelo fato de sua base social - o foreiro - representar uma categoria social ameaçada de extinção. O 'galileu' simboliza o campesinato nordestino que vive próximo aos empreendimentos capitalistas, representando um obstáculo a sua expansão. (BASTOS, 1984, p. 18).
\end{abstract}

Salientamos que a experiência na zona rural de Pernambuco deve ter como forma ilustrativa do prenúncio da mobilização popular em torno das necessidades coletivas dos trabalhadores rurais. Podese dizer, assim, que no Nordeste os galileus foram os precursores das reivindicações dos trabalhadores rurais da região, cujo papel das Ligas era o de mediar a participação popular pelo mecanismo de mobilização social durante os encontros dos trabalhadores, os quais: "Através dos Congressos, superavam o isolamento e o localismo e construíam-se alianças com o espaço urbano, pois as Ligas tinham uma pedagogia" (CHEDINI, 2017, p. 70-71). Dentre as prerrogativas e desdobramentos desse itinerário sociopolítico, cria-se neste período:

A associação - Sociedade Agrícola de Plantadores e Pecuaristas de Pernambuco - SAPP obtém seu registro após um mês. Do ponto de vista legal, caracteriza-se por constituir-se numa sociedade civil beneficente, de auxílio mútuo. Cujos objetivos são, primeiramente, a fundação de uma escola e a constituição de um fundo funerário (as sociedades funerárias são comuns na região) e, secundariamente, a aquisição de implementos agrícolas (sementes, inseticidas, adubos, instrumentos) e reivindicação de assistência técnica governamental. (BASTOS, 1984, p. 19).

É importante registrar que o objetivo principal dessa associação foi o de reivindicar a construção de uma escola e a constituição de um fundo funerário para enterrar os seus mortos na localidade. Em relação à organização social dos movimentos socioterritoriais, o campo se tornou, entrementes, numa importante referência na ampliação do debate sobre a negação do espaço rural com suas demandas territoriais. Consideramos que tais experiências podem ser reiteradas como parte do laboratório da investigação sobre os movimentos camponeses do Brasil:

\footnotetext{
Uma perspectiva evolucionista tem permeado estudos, de brasileiros e não-brasileiros, a respeito dos movimentos sociais no campo. A partir do caso brasileiro, concretamente, tal perspectiva ordena os diferentes movimentos da seguinte maneira: messianismo, como aconteceu em Canudos e no Contestado; banditismo social, como aconteceu no Nordeste com Antônio Silvino e Lampião; associativismo e sindicalismo, como aconteceram com as Ligas Camponesas e com os sindicatos de trabalhadores rurais. (MARTINS, 1986, p. 27).
}

No tocante às Ligas Camponesas, a experiência dos trabalhadores rurais nordestinos remonta os antecedentes do golpe militar de 1964. A autonomia organizacional das classes sociais menos favorecidas do campo se revelou mesmo em face de intensificações políticas do Episcopado e do Partido Comunista Brasileiro - PCB. Na esteira sociopolítica anuncia-se que: "Fato político dos mais importantes na história brasileira é que os movimentos e lutas populares, sobretudo no campo, caminham mais depressa do que os partidos políticos, legais e clandestinos" (MARTINS, 1986, p. 9).

Em princípio, dentro da base originária da composição do campesinato no Brasil, podemos apontar, sociologicamente, nessa trama da formação identitária: "três partes componentes originais do 
campesinato brasileiro são o índio, o trabalhador africano e os europeus não agraciados pela propriedade - a estes se juntavam o sitiante (pequeno agricultor dono de um pedaço de terra)" (MARQUES; MARQUES, 2015, p. 10, grifo do autor). Mediante essa abordagem preliminar sobre a diversidade sociocultural e étnica que compõe o meio rural brasileiro, orientamo-nos da existência de um ethos rural ou modo de ser do camponês, e que tem se reafirmado com sua diversidade sociocultural.

Essa constituição pluriétnica cada vez mais miscigenada vai gestar tipos humanos diferenciados e regionalizados territorialmente, os quais, em suas interações com os ambientes específicos de cada lugar, vão configurar as paisagens com suas peculiaridades culturais: os povos originários, majoritariamente na Amazônia e dispersos nas demais regiões; o sertanejo, no Agreste nordestino; os quilombolas, dispersos em várias regiões; o ribeirinho, às margens de rios; o caipira, em partes do Sudeste; o caboclo, em partes do Nordeste e da Amazônia; o gaúcho, nos pampas sulinos; o colono imigrante europeu, no Sul e em partes do Sudeste, entre outros. Na condição predominante de trabalhadores sem-terra, estão o peão de boiadeiro, o pantaneiro, o agregado, o meeiro, o parceiro e, nas vilas e cidades predominantemente, o boia-fria. (TARDIN, 2012, p. 180).

Mesmo existindo controvérsias históricas, veiculadas ao conceito de camponês na sociedade hodierna brasileira, pretendemos, de modo aproximado, trazer para o debate teórico uma definição circunscrita da multiplicidade das identidades do camponês no Brasil. Faz-se necessário uma interlocução com tais narrativas e suas interpretações simbólicas, principalmente da sua importância no seu espaço ideário da luta política no campo. Desse modo, faz-se notar a presença de identidades que se multiplicaram:

\footnotetext{
O ressurgimento das lutas camponesas nos anos 1980, no final do período militar, configura seu enraizamento no projeto de resistência produzido desde o início da constituição do país. Este projeto, mesmo 'esmagado', é capaz de recolocar-se, agora, como projeto de sujeitos coletivos que produzem identidades. Estas identidades não estão mais referidas às categorias profissionais, mas ao projeto de um grupo específico, surgido na contraposição ao projeto de campo que se instalara com ações e conivência dos governos de então, como os Sem-Terra, os atingidos por barragens, os seringueiros, os pequenos agricultores, entre outros. (CHEDINI, 2017, p. 74-75).
}

Como síntese deste contexto sócio-histórico, o projeto do campesinato vai ser retomado na década de 1980 com o surgimento do Movimento dos Trabalhadores Sem-Terra - MST, no Sul do país; assim sendo, o movimento vai encampar as lutas camponesas anteriores do Nordeste. De modo semelhante, como ocorreu com as Ligas Camponesas que foram cooptadas pela Igreja, o Episcopado se antecipa em face da ameaça do espectro ideológico do comunismo ateu ameaçador. Contudo, os trabalhadores Sem-Terra passaram a ter a sua denominação categórica e suas lutas se espraiaram por todo o Brasil. Cabe, por oportuno, destacar a lição do movimento:

O primeiro elemento diz respeito ao contexto social objetivo em que se insere o nascimento do MST como um todo, com o componente específico da situação educacional brasileira, e particularmente da realidade do meio rural. Assim como não é possível compreender o surgimento do MST fora da situação agrária e agrícola brasileira, também é preciso considerar a realidade educacional do país para entender por que um movimento social de luta pela terra acaba tendo que se preocupar com a escolarização de seus integrantes. (CALDART, 2012, p. 231). 
Dentre os princípios organizativos do MST, convém destacar que a bandeira de luta do movimento encabeçava a luta pela a democratização da terra. Ainda que percebida somente como exigência do discurso normativo, o surgimento da preocupação para com a educação das crianças e jovens ociosos nos assentamentos e acampamentos, particularmente, efetivar-se-ão como modelo de construção do projeto político-pedagógico do próprio movimento. Contudo, é possível perceber que a postura em relação ao sistema educacional da Escola do Campo é desse modo:

Inicialmente, a escola não é prioridade para os trabalhadores sem-terra; ela é uma exigência que se impõe pela realidade das crianças em idade escolar que acompanham os pais durante as ocupações e nas perguntas dessas crianças e desses pais sobre seu futuro. Nesse processo elabora-se uma proposta, inicialmente para a escola básica do campo e, com o avanço das lutas, uma educação do campo. (RIBEIRO, 2013, p. 195).

No contexto educacional, para os trabalhadores Sem-Terra, identificamos que num primeiro momento, o modo de sociabilidade exigia a construção de um novo parâmetro escolar para a Escola do Campo. Nessa primeira fase, o objetivo do movimento visava à implantação dos processos formativos somente para os assentamentos da Reforma Agrária. Posteriormente, aponta-se que os desdobramentos educativos da pedagogia proposta pelos movimentos sociais criaram novas demandas, e a concepção da modalidade educacional passou a ter uma conotação ampliada, tornando-se numa modalidade educacional inovadora, e que integralmente deve ser universalizada para as escolas do campo do Brasil.

\section{A DICOTOMIA DO SABER NA ESCOLA DO CAMPO: APORTES EPISTEMOLÓGICOS DA SOCIOLOGIA RURAL}

A proposta em apresentar a dicotomia do saber na Escola do Campo, a partir da Sociologia rural, objetivou em discutir a perspectiva teórico-política aplicada à Educação do Campo. No que confere ao seu mapeamento na legislação nacional, de acordo com o Decreto $n^{0}$ 7.352/2010, estabelecem-se quais são os atores do campo, bem como a denominação da Escola do Campo. Cumpre-se verificar os esclarecimentos da referida legislação:

\footnotetext{
I - populações do campo: os agricultores familiares, os extrativistas, os pescadores artesanais, os ribeirinhos, os assentados e acampados da reforma agrária, os trabalhadores assalariados rurais, os quilombolas, os caiçaras, os povos da floresta, os caboclos e outros que produzam suas condições materiais de existência a partir do trabalho no meio rural; e

II - escola do campo: aquela situada em área rural, conforme definida pela Fundação Instituto Brasileiro de Geografia e Estatística - IBGE, ou aquela situada em área urbana, desde que atenda predominantemente a populações do campo. (BRASIL, 2010, Art. 1. § $1^{\circ}$ ).
}

Levando-se em conta o que foi estabelecido pelo decreto, é possível observarmos as relações sociais associadas à produção material no campo. Dessa forma, o documento sugere uma diversidade social que engloba as populações do campo e que por ventura pode ser aplicada a modalidade educacional. Por outro lado, a Escola do campo também deverá atender aos parâmetros geográficos 
preestabelecidos. Identificamos no bojo do referido decreto, identidades híbridas e pluriétnicas, mas que comungam pelo viés do trabalho.

Passados trinta anos da luta pela redemocratização do país, as concepções pedagógicas inovadoras são frutos das lutas contemporâneas, evidenciando-se em modalidades educacionais que foram adotadas com a função de equacionar as disparidades regionais do ensino ofertado pela Escola Formal. A Educação do Campo surge como um modelo contra-hegemônico com a promessa de minimizar as discrepâncias existentes entre o ensino e a aprendizagem da Escola do Campo. Para tal superação é necessário outro reposicionamento da educação, uma vez que sabemos que particularmente:

"[...] à função de 'hegemonia' que o grupo dominante exerce em toda a sociedade e àquela de 'domínio direto' ou de comando, que se expressa no Estado e no governo 'jurídico'. Estas funções são precisamente organizativas e conectivas". (GRAMSCI, 2001, p. 21, grifo do autor).

Ao observamos o interior da Escola do Campo, a educação hegemônica legitima a internalização fatalista da hierarquia social que reproduz o projeto educacional da burguesia. No tocante à reprodução social, sabemos que as novas tecnologias educativas não estão disponíveis para todos. $\mathrm{E}$ os desafios consistem em querer transformar o sistema operacional vigente, que por muito tempo permaneceu sedimentado, em privilégios de conteúdos para realidades distintas de outras regiões do país. Sob a crítica dessa natureza seletiva de uma educação etnocêntrica pousa o seguinte:

Do ponto de vista prático, trata-se de retomar vigorosamente a luta contra a seletividade, a discriminação e o rebaixamento do ensino das camadas populares. Lutar contra a marginalidade através da escola significa engajar-se no esforço para garantir aos trabalhadores um ensino da melhor qualidade possível nas condições históricas atuais. O papel de uma teoria crítica da educação é dar substância concreta a essa bandeira de luta de modo a evitar que ela seja apropriada e articulada com os interesses dominantes. (SAVIANI, 1982, pp. 16-17).

Neste quadro panorâmico, podemos observar que existem contradições teóricas acerca das competências pedagógicas que são apropriadas aos interesses dominantes. Com isso, as respostas são extraídas de um sistema antitético que atua em benefício próprio. Consequentemente, os sujeitos podem ser induzidos ao erro por estarem em situação de marginalizados e por pertencerem às classes populares. Por conseguinte, identificam-se os aspectos esquadrinhados do dualismo de um saber que hierarquizam os processos educativos, simplificadamente, de modo acrítico. Entretanto, como parte integrante da etnologia rural, cada população está submetida às interferências das nuanças históricas. No dizer sempre expressivo do educador brasileiro:

O trabalhador, não sendo proprietário dos meios de produção, mas apenas de sua força de trabalho não pode, portanto, se apropriar do saber. Assim, a escola pública, concebida como instituição de instrução popular destinada, portanto, a garantir a todos o acesso ao saber, entra em contradição com a sociedade capitalista. (SAVIANI, 2005, p. 257).

De mesmo modo, o sistema escolar urbano e rural é pautado sobre as bases convencionadas de uma racionalidade dualista disposta a recriar modelos antagônicos como forma de fragmentar historicamente o conhecimento. Neste enquadramento, a tendência é perder tempo em traçar 
dicotomias que aparecem como um obstáculo epistemológico que envolve a escola brasileira numa relação paradoxal, assim o desafio reside em buscar outros instrumentos educativos:

Somente o raciocínio dialético permite observar como os objetos reais se interpenetram de forma ora articulada ora integrada, mas sempre compondo com a totalidade. Superar a razão dualista é, portanto, o primeiro passo para compreender como se articulam o rural e o urbano no Brasil de hoje. (WHITAKER, 2008, p. 283).

Tal concepção de mundo espraia-se nos conteúdos escolares como modelo cognoscente da cultura urbano-científica. Nesse expediente da evidência da educação urbano-centrada, encontramos uma racionalidade dualista que guia coercitivamente os sujeitos durante todo o período escolar. Destarte, o grande desafio é fazer com que o ensino e o aprendizado através da Educação do Campo sejam, de fato, um modelo necessário e não contingencial para o território rural. O distanciamento entre teoria e prática é condição circunscrita que reforça a lógica dualista de um modelo educacional desigualitário para o sujeito do campo.

Nesse palco de desigualdade educacional, o conhecimento hegemônico advoga que o ensino e a aprendizagem devem operar, predominantemente, associados ao modo de vida da cidade. Por conseguinte, a internalização desse currículo oculto resulta num arranjo educacional mediado por uma troca desigual sobre o modo de vida no campo. Semelhantemente, sabemos que a Educação Formal é uma só, no entanto, se faz necessário pisar no chão da sala de aula para compreender do que estamos a tratar. Em vista disso, a explicação simplista, mas altamente significativa, registra os interesses idiossincráticos do sistema educacional adotado para a Escola do Campo do Brasil. A educação é perscrutada, adequando-se aos aspectos pedagógicos dos limites antagônicos para perpetuar a submissão aliada ao pensamento urbano científico.

\footnotetext{
O que tem isso de errado? Em princípio, nada. A escola tem mesmo que ensinar as bases matemáticas da ciência ocidental, a norma culta da linguagem e a História Oficial, porque é desses conteúdos que as pessoas necessitam para conquistar a cidadania numa sociedade que se diz moderna. O problema está em que a escola brasileira não estabeleceu condições para fazer a conexão entre esses conteúdos culturais e aqueles que parecem 'menores', mas existem em maior quantidade na sociedade nacional. (WHITAKER, 2008, p. 286).
}

Como o espaço do aprendizado é tutelado, inibem-se as potencialidades cedendo lugar para as determinações de uma lógica nociva centrada no mundo de outrem. Embora tenhamos delineado que o rural e o urbano se interpenetram, há que considerar que se depreende a predominância sucessiva do saber colonizado de forma desigual na estrutura educacional. Devemos notar, assim, que no campo da Sociologia Rural, o dualismo rural-urbano deve ser superado dentro da abordagem sobre o território, enfatiza-se que:

[...] o meio rural não pode nunca ser estudado em si mesmo, mas deve ser encarado como parte de um conjunto social mais amplo, do qual faz parte juntamente com a cidade. Do mesmo modo, toda sociologia urbana não pode deixar de englobar o aspecto rural ao formular seus problemas, pois a cidade está sempre implantada no campo, tendo para com este relações de variada forma, desempenhando funções diferentes em relação a ele, conforme o caso em foco. (QUEIROZ, 1972, p. 203-204).

Não se pode negar que o desenvolvimento do rural pela via da Educação Escolar do Campo vai reverberar no quadro da competitividade mercadológica, onde o rural se tornou o centro das 
atenções num mundo cada vez mais globalizado economicamente. Todavia, o caminho para viabilizar tal transformação no sistema escolar não dependerá de modelos exógenos, pois existe:

\begin{abstract}
Um outro aspecto da questão - do qual a Sociologia nem sempre se dá conta - e este vai ser o mais importante para se discutir a educação rural (e urbana) é o fato de que, ao avançar pelo campo, através do complexo agroindustrial, o capitalismo não só não urbaniza o campo como desurbaniza as pequenas cidades da região, que se transformam em cidades-dormitório de trabalhadores volantes. É um processo, portanto de desruralização e de desurbanização. (WHITAKER, 2008, p. 285).
\end{abstract}

Por entendermos que o território rural-urbano é a totalidade das ações humanas dispostas sob um determinado espaço geográfico, e que por sua dinâmica socioambiental acaba se reelaborando, traz consigo novas abordagens. Porém, como se nota, as dicotomias construídas a partir da produção do conhecimento, por vezes são operacionalizadas para formar sujeitos cada vez mais desterritorializados. Nesse sentido, subentende-se que a escola, como centro de formação social, oblitera-se a diversidade dos atores sociais com conteúdos distantes e alheios à realidade do território local. Neste caso:

Continua urbanocêntrica, sociocêntrica e etnocêntrica. Digo etnocêntrica pra não dizer racista, já que continua voltada aos interesses de uma elite branca que até hoje não conseguiu resolver nem os problemas do analfabetismo no país. Diga-se de passagem, a escola não tem culpa como escola. Ela é assim porque as classes dominantes (das quais saem os técnicos do MEC) são assim. (WHITAKER, 2008, p. 287).

Por ordem idealizadora das matrizes: urbanocêntrica, eurocêntrica e etnocêntrica, o modelo de escolarização circunscrito para os territórios rurais sempre teve como instrumentalização intelectual e política, o investimento em programas, propagandas e estratégias exógenas que, consequentemente, reforçam a lógica da colonialidade do saber, empregando-se a condição de subalternidade como condição natural do sujeito do campo. Urge retomarmos uma postura crítica em relação à promessa da sociedade urbanizada que prega as dissemelhanças da posição inferiorizada do campo em relação à cidade:

\begin{abstract}
As relações campo-cidade no Brasil são atualmente muito mais complexas e ricas do que no passado. No momento presente, processos recentes de ocupação do solo (por meio da especulação imobiliária, por exemplo), coexistem com antigos processos (desbravamento, colonização), tanto por parte de fazendeiros quanto de sitiantes; num e noutro caso, tais processos foram sempre suscitadores de cidades. Mas, enquanto no passado se davam numa sociedade global agrária, em que a cidade era subordinada ao campo, atualmente têm lugar numa sociedade cada vez mais marcada por caracteres urbanos, onde a cidade tende cada vez mais a dominar o campo, reduzido a uma posição, não apenas de subordinação, mas também de inferioridade. (QUEIROZ, 1972, p. 216-217).
\end{abstract}

Nesse percurso, quando propomos tratar da existência ou não de um retrato que expresse a condição identitária de uma estética camponesa, a preocupação humanista com a vida cotidiana nos remete para as recomendações do potencial pedagógico subjacente da aplicação da instrução em escala real, sobre uma base local. Nesta experiência, especificamente, acaba-se se tornando proeminente expressar a essência do trabalho rural como um instrumento epistemológico de descobertas para os sujeitos numa condição de pertencimento, que continuamente podem, com sua tendência de integração com a natureza, ampliar o conhecimento histórico sobre a sua realidade no campo. 
A interação dialética que precede dessa relação opera antecipadamente a todas as formas de sociabilidades, inclusive, é parte inerente da construção identitária dos povos do campo. Mas a fragmentação dessa ação na vida cotidiana moderna é identificada a partir da coexistência de indefinições de uma identidade cindida e descompromissada, e que tem negado essa realidade geograficamente. As variáveis conceituais que dividem o campo (zona rural) da cidade (zona urbana) são arbitrárias, entendendo-se que os territórios não são homogêneos, mas convergentes, guardadas as diferenças espaciais.

Quando encaramos a relação rural-urbana da maneira acima exposta, abandonamos a perspectiva habitual, que é a de duas realidades paralelas, embora interligadas, formando duas sociedades globais fundamentalmente diferentes. Admitimos, ao contrário, que numa sociedade global a estrutura e a organização podem reunir em arranjos variados ou três tipos sociais, ou dois destes, variando o grau de dominação de cada um, e formando tais sociedades complexos sincréticos. Em cada um destes será necessário descobrir o tipo predominante, e de forma se interpenetra com os outros para formar a configuração existente. (QUEIROZ, 1972, p. 202 - 203).

A observação descrita nos remete a face enviesada de um modelo educativo com fins pedagógicos específicos. Desse modo, não podemos omitir que as adaptações aos modelos de escolarização no campo têm sido adequadas às necessidades momentâneas de sustentação do próprio modelo doutrinário econômico. Dessa forma, torna-se necessária a retomada da crítica à educação urbano-centrada que tem sido apreendida como uma forma mercadológica do sistema de reprodução social. Para fazer uma contraposição ao modelo vigente, o ensinar e aprender na Escola do Campo propõ-se uma educação para além dos limites do capitalismo impostos para as populações pobres do campo. Não obstante, é necessário legitimar as alternativas sustentáveis da política da Educação do Campo e da contribuição do ethos rural, como um elemento estruturante para o desenvolvimento das ações educativas. Nesse sentido, tem-se o entendimento de que:

\footnotetext{
O trabalho educativo é o ato de produzir, direta e intencionalmente, em cada indivíduo singular, a humanidade que é produzida histórica e coletivamente pelo conjunto dos homens. Assim, o objeto da educação diz respeito, de um lado, à identificação dos elementos culturais que precisam ser assimilados pelos indivíduos da espécie humana para que eles se tornem humanos e, de outro lado e concomitantemente, à descoberta das formas mais adequadas para atingir esse objetivo. (SAVIANI, 2011, p. 13).
}

Desse modo, o trabalho educativo não é para tornar o educando, meramente, um buscador para validar suas capacidades e habilidades para manter a força de trabalho. Mas que se busque, sobretudo, a sua emancipação e seu lugar de participação coletiva no movimento social, na escola ou na comunidade. É necessária uma ruptura do projeto colonizador para recorrer às outras narrativas do conhecimento de si mesmo e do território.

A luta por um protagonismo do campo em face à pedagogia da hegemonia, num primeiro momento, é necessária, para que haja um rompimento com os estigmas reproduzidos no ambiente rural, os quais são concebidos pelos traços fortes impressos no meio rural, como um lugar de pobreza e miserabilidade. Num segundo momento, o aprendizado deve ser capaz de fazer uma superação radical para exercer o enfrentamento a esta contradição ideológica do pensamento urbano-científico proposta pela Educação Formal. Reiteramos que, em relação à formação de educadores do Campo, esta não deve ser tratada diferentemente da formação de educadores da Educação Urbana. Contudo, 
pode ser pensada como uma forma de reparar o desenraizamento na formação do próprio educador, onde:

O ensino deveria ser mais flexível e culturalmente adaptado do que é, tanto no campo quanto na cidade. A educação básica na cidade é quase que apenas projeção da ideologia de classe média do educador. O mesmo acontece no campo. Prevalece ainda entre nós a concepção de que o educador não precisa ser educado, não precisa ser ressocializado para a sua missão de educar. (MARTINS, 2005, p. 31).

\section{CONSIDERAÇÕES FINAIS}

Dentro dos critérios epistemológicos da Sociologia rural, nosso trabalho objetivou fazer uma prospecção das possibilidades de abrangência para a compreensão da Educação do Campo no território rural. Pretendeu-se, com a investigação analisar preliminarmente, a relação entre a política da Educação Escolar do Campo e a dicotomia educacional do rural-urbano no contexto do processo de construção de saber pedagógico. Entretanto, quando se pensa em dissociar a formação dos educadores do campo em relação aos educadores que atuam na cidade, em consonância com a lição, sempre precisa da Sociologia Rural:

\footnotetext{
Eu não dividiria o mundo em rural e urbano. Pois, seguindo essa lógica, eu poderia perguntar se a formação do professor da periferia urbana deteriorada deveria ser a mesma do professor que vai trabalhar nas regiões mais afluentes das cidades. Pessoalmente, acho que todos os professores do ensino básico, sem distinções, deveriam receber uma formação sociológica e antropológica. De modo que eles próprios tivessem condições de se reciclar e ajustar em face das situações cambiantes de trabalho educativo que encontram pela frente, na cidade e no campo. (MARTINS, 2005, p. 35).
}

A interação do meio rural como elemento constitutivo da materialidade da Educação do Campo, insere-se, precipuamente, dentro das impertinências identitárias dos movimentos sociais do campo. Por outro lado, teoricamente, a aglutinação elementar da identidade do meio rural na Escola do Campo, tende a ser ressignificada como uma contraposição ao modelo de escolarização hegemônica imposta pela cultura citadina.

Ao contrário dessa homogeneização do sistema escolar hegemônico, a discussão da Educação do Campo perpassa por um quadro de resistência das práticas pedagógicas vigentes. A questão educativa é acrescida pelos nexos históricos da mobilização social dos movimentos socioterritoriais que engendraram a possibilidade da constituição de outro projeto de campo. Com efeito, a modalidade educacional dos assentamentos e acampamentos rurais se espraiou para além da atuação geográfica dos movimentos.

Parece-nos importante destacar que, para os movimentos socioterritoriais, a percepção da Escola do Campo passa por outra perspectiva e não deve ser confundida com a antiga Escola Rural, pois essa distinção não tem atendido aos pressupostos do projeto de Educação do Campo. Depreende-se dessa concepção, como uma forma de combater a precariedade entre o ensino e a aprendizagem, bem como ocupar os espaços da Escola do Campo, que, permanentemente, tem sofrido com o fechamento e a paralização das atividades educacionais. 
Vale sublinhar que a educação urbano-centrada tem sido explicitada por meio de equívocos, principalmente quanto à sistematização do conteúdo escolar no tocante a escolarização ofertada para a Escola do Campo. Neste debate, ao romper com o paradigma vigente do sistema de ensino, a modalidade da Educação do Campo não deve deslegitimar a Educação Urbana, posto que não pode ser pensada sem compreender sua indissociabilidade e sua hegemonia. Evidentemente que não devemos privilegiar uma modalidade em detrimento de outra, pois a apropriação do conhecimento acumulado pela humanidade durante a formação educacional não deve ser burocratizada pelo saber dualista, além disso, é necessária à adoção de práticas pedagógicas mais abrangentes do ponto de vista da cultura dos envolvidos.

Diante dos desafios descritos neste texto, podemos afirmar que o preconceito sobre o modo de vida rural interfere diretamente na capacidade de transformação social, podendo agravar ainda mais a condição de subalternização dos sujeitos do campo. No contexto da instrução pública, o dilema é antigo, dado que invocam ações educativas imediatistas, dificultando o acesso da educação a uma grande massa de excluídos. É provável que tudo isso faça parte do predomínio colonizador urbanocentrado, em que o modo de deseducar faz parte do projeto de controle para a manutenção do saber hegemônico.

$\mathrm{Na}$ medida em que a crise provocada na educação brasileira suscita problemas cognitivos, epistemológicos e também subjetivos, notamos que o recrudescimento ideológico de novos projetos para a Escola que propõe práticas educativas proibitivas, orientadas pelos princípios e valores morais da família, da religião e da cidade, está em crescente demasia. O que nos preocupa é a repercussão que ecoam como práticas pedagógicas cotidianas de uma Escola Livre, mas ideologicamente aprisionada em seus intramuros de preconceitos obsoletos.

\section{REFERÊNCIAS}

1. BASTOS, Élide Rugai. As Ligas Camponesas. Petrópolis - Rio de Janeiro: Vozes, 1984.

2. BRASIL. Presidência da República. Decreto no 7.352, de 4 de novembro de 2010: dispõe sobre a Política Nacional de Educação do Campo e sobre o Programa Nacional de Educação na Reforma Agrária. Brasília, Diário Oficial da União, 4 nov. 2010. Disponível em: <http://portal.mec.gov.br/docman/marco-2012-pdf/10199-8-decreto-7352-de4-de-novembro-de2010/file>. Acesso em: 20 nov. 2018.

3. CALDART, R. S. Pedagogia do Movimento Sem Terra. São Paulo: Expressão Popular, 2012.

4. CHEDINI, Cecília Maria. A Produção da Educação do Campo no Brasil: das Referências Históricas à Institucionalização. Jundiaí: Paco Editorial, 2017. 
5. COSTA, Francisco de Assis; CARVALHO, Horácio Mantins de. CAMPESINATO. In: CALDART, Roseli Salete; PEREIRA, Isabel Brasil; ALENTEJANO, Paulo; FRIGOTTO, Gaudêncio (Orgs.). Dicionário da Educação do Campo. Rio de Janeiro, São Paulo: Escola Politécnica de Saúde Joaquim Venâncio. Expressão Popular, 2012.

6. GRAMSCI, Antonio. Cadernos do cárcere, volume 2. Edição e tradução, Carlos Nelson Coutinho; coedição, Luiz Sérgio Henriques e Marco Aurélio Nogueira. $2^{\mathrm{a}}$ ed., Rio de Janeiro: Civilização Brasileira, 2001.

7. GRAMSCI, Antonio. Cadernos do cárcere, volume 1. Edição e tradução, Carlos Nelson Coutinho; coedição, Luiz Sergio Henriques e Marco Aurélio Nogueira. Rio de Janeiro: Civilização Brasileira, 1999.

8. MARTINS, José de Souza. Cultura e educação na roça, encontros e desencontros. Revista USP, São Paulo, n. 64., fevereiro. 2005. Disponível em: <http://www.revistas.usp.br/revusp/issue/view/1065>. Acesso em: 2 nov. 2018. Doi: https://doi.org/10.11606/issn.2316-9036.v0i64p28-49.

9. MARTINS, José de Souza. Os Camponeses e a política no Brasil: As lutas sociais no campo e seu lugar no processo político. Petrópolis - RJ: Vozes, 1986.

10. MARQUES, Gilberto de Souza; MARQUES, Indira Rocha. Luta camponesa e reforma agrária no Brasil. São Paulo: Sundermann, 2015.

11. QUEIROZ, Maria Isaura Pereira de. Do rural e do urbano no Brasil. In. SZMRECSÁNYI, Tamás; QUEDA, Oriowaldo (Orgs.). Vida rural e mudança social. São Paulo: Editora Nacional, 1972.

12. RIBEIRO, Marlene. Movimento camponês, trabalho e educação, liberdade, autonomia, emancipação: princípios/ fins da formação humana. São Paulo: Expressão Popular, 2013.

13. SAVIANI, Dermeval. Pedagogia Histórico-Crítica: primeiras aproximações. Campinas, SP: Autores Associados, $11^{\text {a }}$ ed., 2011.

14. SAVIANI, Dermeval. As Teorias da Educação e o problema da marginalidade na América Latina. Caderno de Pesquisa, São Paulo, n. 42, agosto. 1982. ISSN 0100-1574. Disponível em: <http://publicacoes.fcc.org.br/ojs/index.php/cp/article/view/1546>. Acesso em: 5 dez. 2018. Doi:https://orcid.org/0000-0002-3148-3055. 
SAVIANI, Dermeval. Educação socialista, pedagogia histórico-crítica e os desafios de uma sociedade de classes. In: LOMBARDI, José Claudinei; SAVIANI, Dermeval (Orgs.) Marxismo e Educação: debates contemporâneos. Campinas: Autores Associados, 2005.

16. TARDIN, José Maria. CULTURA CAMPONESA. In: CALDART, Roseli Salete; PEREIRA, Isabel Brasil; ALENTEJANO, Paulo; FRIGOTTO, Gaudêncio (Orgs.). Dicionário da Educação do Campo. Rio de Janeiro, São Paulo: Escola Politécnica de Saúde Joaquim Venâncio. Expressão Popular, 2012.

17. WHITAKER, Dulce Consuelo Andreatta; FIAMENGUE, Elis Cristina. Ciência e Ideologia: as armadilhas do preconceito. In: WHITAKER, Dulce Consuelo Andreatta (Org.). Sociologia Rural Questões Metodológicas Emergentes. Presidente Venceslau, São Paulo: Letras à Margem, 2002.

18. WHITAKER, Dulce Consuelo Andreatta. O Rural-Urbano e a Escola Brasileira. Revista Retratos de Assentamentos, Araraquara, n.11, 2008. ISSN 1516-8182. Disponível em: <http://www.uniara.com.br/nupedor/revista-retratos/>. Acesso em: 10 mar. 2019. Doi: https://orcid.org/0000-0001-9798-3071.

\section{Manoel Valquer Oliveira Melo}

Doutorado em Desenvolvimento Territorial e Meio Ambiente pela Universidade de Araraquara.

\section{Oriowaldo Queda}

Doutorado em Agronomia pela Escola Superior de Agricultura Luiz de Queiroz.

Vera Lúcia Silveira Botta Ferrante

Doutorado em Sociologia pela Universidade Estadual Paulista Júlio de Mesquita Filho.

\section{Como citar este documento:}

OLIVEIRA MELO, Manoel Valquer; QUEDA, Oriowaldo; SILVEIRA BOTTA FERRANTE, Vera Lúcia. A dicotomia do Saber na Escola do Campo: aportes Epistemológicos da Sociologia Rural. Reflexão e Ação, Santa Cruz do Sul, v. 28, n. 2, jun. 2020. ISSN 1982-9949. Disponível em: <https://online.unisc.br/seer/index.php/reflex/article/view/14312>. Acesso em: doi:https://doi.org/10.17058/rea.v28i2.14312. 